\title{
Las políticas de ciudadanía en los estados del Consejo de Cooperación del Golfo
}

\author{
Luciano Zaccara y Marta Saldaña*
}

\section{Resumen}

Este artículo explora los marcos legales de ciudadanía y naturalización de los seis estados del Consejo de Cooperación del Golfo, y analiza cómo han sido utilizados desde el establecimiento de los estados modernos hasta la actualidad, con especial atención a los acontecimientos posteriores a la Primavera Árabe. En este contexto, se investiga en qué medida ha afectado el carácter rentista de los estados del Golfo al diseño de sus políticas de ciudadanía y naturalización; cuáles son los principales aspectos de dicha legislación en cada país; qué diferencias hay entre la utilización de los marcos legales antes y después de la Primavera Árabe; qué reformas legales se han llevado a cabo tras de la Primavera Árabe; y con qué objetivos se ha concedido o revocado la ciudadanía. El artículo concluye que las políticas de ciudadanía de los estados del CCG han sido un aspecto fundamental de la construcción del Estado-nación y del establecimiento de la relación Estado-sociedad, así como parte esencial de una muy elaborada estrategia para garantizar la estabilidad, supervivencia y legitimación de los regímenes políticos, con mayor énfasis desde la Primavera Árabe.

\section{Palabras CLAVE}

Ciudadanía; naturalización; Primavera Árabe; Consejo de Cooperación del Golfo.

\section{TitLe}

Citizenship Policies in the Gulf Cooperation Council States

\section{Abstract}

This article explores the legal frameworks of citizenship and naturalization of the six states of the Gulf Cooperation Council, and analyzes how they have been used since the creation of modern states to the present, with special attention to events after the Arab Spring. Within this context, it discusses to what extent the rentier character of the Gulf states has affected the design of policies of citizenship and naturalization; which are the main aspects of the legislation of each country; what are the differences between the use of legal frameworks before and after the Arab Spring; what legal reforms have been carried out since the Arab Spring; and with what objectives has citizenship been granted or revoked. The article concludes that the citizenship policies of the GCC states have been a fundamental aspect of the nation-state building process and the establishment of state-society relations, as well as of a very elaborate strategy to ensure political regime stability, survival and legitimization, especially visible in the aftermath of the Arab Spring.

\section{KEYWORDS}

Citizenship; Arab Spring; Gulf Cooperation Council.

* Luciano ZACCA-

RA, Research Assistant Professor, Cen-tro de Estudios del Golfo, Qatar Univer-sity. Investigador visitante, George-town University en Qatar, Investigador visitante University of Exeter, Reino Unido. Director Ob-servatorio Político y Electoral del Mundo Árabe y MusulmánOPEMAM, Madrid. Su correo electró-nico es: luciano.

zaccara@qu.edu.qa

Marta SALDAÑA Investigado-ra Postdoctoral, Universidad de Georgetown en Qatar. Doctorado en Política de Oriente Medio, Universidad Autónoma de Ma-drid y Universidad de Exeter (Reino Unido). Su correo electrónico es: ms3907@georgetown.edu

Esta publicación fue posible gracias a la subvención PDRA \# 2-111714120 del Qatar National Research Fund (miembro de Qatar Foundation). Los resultados obtenidos son responsabilidad exclusiva de los autores.

Recibido:

2016-11-22

Aceptado:

2017-01-17

DOI: $10.15366 /$

relacionesinternacio nales2017.35.004 


\section{ntroducción}

El concepto de ciudadanía es relativamente nuevo en los estados del Consejo de Cooperación del Golfo (Arabia Saudí, Kuwait, Omán, Bahréin, Qatar y Emiratos Árabes Unidos). Con excepción del reino saudí, que fue oficialmente creado en 1932, los restantes fueron creados entre la década de los 60 y 70, por lo que las políticas de ciudadanía tuvieron que ser diseñadas a partir del establecimiento de nuevas fronteras y teniendo como referencia hitos históricos específicos para determinar quienes tenían derecho a ser ciudadanos de los estados recientemente creados. Esto entraría en contradicción con la estructura tribal transnacional y la heterogeneidad étnica y religiosa de las sociedades de la Península Arábiga, lo que ha creado no pocas controversias a lo largo de los últimos cuarenta años, y también decisiones arbitrarias de concesión de ciudadanía a grupos específicos de población. Lo que se desprende de estas políticas es que la ciudadanía se considera como una gracia del Estado y no como un derecho inalienable, y que por lo tanto puede ser concedida y revocada al criterio de los gobernantes. Esto ha sido notable históricamente en los procesos de naturalización de determinados grupos de inmigrantes, basado en consideraciones demográficas, políticas, de parentesco y de género (para mantener equilibrios entre grupos étnicos o religiosos, o para garantizar la lealtad de una determinada tribu que serviría como fuerza militar o de seguridad). Más recientemente, y sobre todo desde la Primavera Árabe, la promulgación de leyes de seguridad del Estado ha permitido la concesión o revocación de ciudadanía como estrategias de control del disenso político.

Este artículo, explora los marcos legales de ciudadanía y naturalización de estos seis estados, y analiza cómo han sido utilizados desde el establecimiento de los estados modernos hasta la actualidad, con especial atención a los acontecimientos posteriores a la Primavera Árabe. En este contexto, y a lo largo de la evolución política de las seis monarquías desde su creación hasta la actualidad, pasando por los acontecimientos de la Primavera Árabe que deslegitimaron y generaron una ola de cambio político en el mundo árabe, se intenta responder a las siguientes preguntas:

¿En qué medida ha afectado el carácter rentista de los estados del Golfo al diseño de sus políticas de ciudadanía y naturalización?

¿Cuáles son los principales aspectos de la legislación que regula la ciudadanía y naturalización en cada estado y cuáles son las principales diferencias entre unos y otros?

¿Qué diferencias hay entre la utilización de los marcos legales de ciudadanía y naturalización antes y después de la Primavera Árabe?

¿Qué reformas legales se han llevado a cabo después de la Primavera Árabe que afecten a las políticas de ciudadanía y naturalización?

¿Con qué objetivos se ha concedido o revocado la ciudadanía en los distintos estados tras la Primavera Árabe?

El artículo concluye que, si bien las políticas de ciudadanía de los estados del CCG han sido un aspecto fundamental de la construcción del Estado-nación, y del establecimiento de la relación Estado-sociedad, así como parte esencial de una muy elaborada estrategia para 
garantizar la estabilidad, supervivencia y legitimación de los regímenes políticos, con mayor énfasis desde la Primavera Árabe.

El trabajo de campo para este artículo se ha realizado en Emiratos Árabes Unidos, Qatar, Omán, Bahréin y Kuwait entre 2011 y 2016. El mismo ha incluido entrevistas semiestructuradas con ciudadanos de los seis estados, funcionarios e investigadores nacionales y extranjeros. También se ha entrevistado a algunas personas afectadas directa o indirectamente por las medidas restrictivas mencionadas a lo largo del artículo. Debido a la sensibilidad del tema, los entrevistados se han mantenido en el anonimato. Las fuentes primarias utilizadas provienen de traducciones oficiales y semi-oficiales al inglés, y en algunos casos directamente del árabe. También se ha recurrido a fuentes periodísticas contrastadas, y se ha revisado la bibliografía más pertinente y actualizada en el ámbito de los estudios del Golfo.

\section{Rentismo, ciudadanía e identidad nacional en el CCG}

Los países del Consejo de Cooperación del Golfo $^{1}$ (CCG) son casos únicos en los procesos de creación del Estado, construcción de las identidades nacionales y diseños de las políticas de ciudadanía. En este sentido, tanto el descubrimiento de hidrocarburos y las relaciones establecidas con las potencias extranjeras, principalmente Gran Bretaña, han sido factores críticos en la reconfiguración de la demografía y las relaciones Estado-sociedad de estos países. Las actividades comerciales y fluctuaciones en las poblaciones que se sucedieron durante siglos en la región desafían las generalmente aceptadas concepciones de que las 'gentes del Golfo' (jaliyi) vivieron aisladas hasta el descubrimiento del petróleo, y proveen en cambio una explicación para su diversa procedencia cultural ${ }^{2}$. Es un hecho documentado que diversos grupos vivieron en la región al menos desde el siglo VI, y que desarrollaron vías marítimas y terrestres de comercio que los conectaron con otras zonas de la península Arábiga, Oriente Medio, Asia Central y del sur, el este de África e incluso el Extremo Oriente ${ }^{3}$. Dentro de este contexto, la fluctuación de poblaciones en ambas orillas del Golfo y con puertos a lo largo del Océano Índico fue muy común, y los diferentes grupos étnicos coexistieron y se mezclaron contribuyendo al carácter multicultural de las sociedades del Golfo pre-petroleras.

Sin embargo el rápido desarrollo socio-económico y los crecientes flujos migratorios que siguieron al descubrimiento del petróleo demandaron el establecimiento de estados modernos, con sus fronteras claramente delimitadas, y el desarrollo de legislaciones que regularan qué habitantes y territorios pertenecían a cada una de las seis monarquías. La población era en principio reducida, con escasos recursos económicos y mayormente iletrada, lo que contribuyó a que la evolución de la relación Estado-ciudadanía no fuera en principio

\footnotetext{
1 El Consejo de Cooperación para los Estados Árabes del Golfo, denominada habitualmente con su original nombre de Consejo de Cooperación del Golfo, es una organización regional creada el 25 de mayo de 1981, y compuesta por las monarquías de Bahréin, Kuwait, Omán, Qatar, Arabia Saudita y los Emiratos Árabes Unidos.

2 Aunque existe un consenso entre los estudiosos del tema de que los árabes descienden de mismo grupo étnico, esto no significa que las gentes del Golfo han sido siempre y únicamente árabes. ANANI, Ahmad, WHITTINGHAM, Ken, The Early History of the Gulf Arabs, Longman, Londres y Nueva York, 1986; WILKINSON, John Craven, Water and tribal settlement in South-East Arabia, Clarendon, Oxford, 1977.

3 AGIUS, Dionisius, "The Rashayda: Ethnic identity and dhow activity in Suakin on the Red Sea coast" en Northeast African Studies, n012/1, 2012, pp. 169-216; PETERSON, John E., "Oman's diverse society: Southern Oman" en The Middle East Journal, no 58/2, 2004, pp. 254-269; POTTS, Daniel T., Ancient Magan: The Secrets of Tell Abraq, Trident, London, 2000; ZAHLAN, Rosemarie Said, The Making of the Modern Gulf States: Kuwait, Bahrain, Qatar, the United Arab Emirates and Oman, Garnet \& Ithaca Press, Reading, 1998.
} 
conflictiva. Se convirtió en cambio en una relación patrón-cliente basada en una economía rentista que comprendió desde el principio un generoso estado de bienestar. Por una parte, la legitimidad otorgada por las potencias extranjeras a los gobernantes locales los pusieron en una posición fuerte y segura desde donde ejercer el poder absoluto sobre sus territorios y poblaciones. Por otra parte, y como lo explica la Teoría del Estado Rentista (TER), que pone el énfasis en la renta externa como principal factor en la formación de las estructuras y dinámicas estatales, los ingresos provenientes del petróleo permitieron a los gobernantes ser económicamente independientes, permitiéndoles desarrollar una nueva relación con sus ciudadanos de proveedores de servicios sociales y subsidios sin la existencia de impuestos ${ }^{4}$. El contrato social resultante fue el centro de los diseños de las políticas de ciudadanía en el Golfo, y también de los sistemas políticos que otorgaban muy limitados derechos políticos.

En este contexto, surgieron diversos niveles de beneficiarios condicionados por los orígenes tribales y étnicos, así como por su afiliación religiosa. A la vez que los ingresos por el petróleo y la poblaciones comenzaron a crecer drásticamente, las políticas de ciudadanía y naturalización comenzaron a ser diseñadas para limitar el acceso a los beneficios del estado de bienestar. Simultáneamente, los monarcas del Golfo se dedicaron a construir la identidad nacional, fortaleciendo el sentimiento de pertenencia, que sirviera también como elemento legitimador de sus gobiernos. Ignorando en gran parte el histórico carácter multicultural de sus sociedades, las nuevas narrativas fueron cuidadosamente diseñadas alrededor de la figura de los gobernantes y su rol de proveedores de bienestar. Más aún, para reducir cualquier potencial desafío a sus legitimidades, enfatizaron la herencia tribal árabe (principalmente sunní, con la excepción de Omán, donde hay mayoría ibadí) de la que las familias gobernantes descendían ${ }^{5}$. Del mismo modo, las legislaciones de ciudadanía y naturalización establecieron criterios de elegibilidad basados en el parentesco (jus sanguinis), y la filiación territorial, étnica y lingüística. Por lo tanto, estando entre las más restrictivas del mundo, dichas legislaciones limitan el acceso a individuos pertenecientes a una identidad muy específica, favoreciendo la formación de una sociedad jerárquicamente estratificada entorno a líneas étnicas, religiosas, ocupacionales y de ingresos, donde los 'nacionales' se han convertido en una minoría privilegiada, y en donde la brecha entre nacionales/no nacionales es de las más grandes del mundo ${ }^{6}$.

\section{EI marco legal de las ciudadanías del CCG}

El concepto de ciudadanía, y los marcos legales que las definen y regulan son relativamente nuevos en los estados del Consejo de Cooperación del Golfo. Con excepción del reino de

\footnotetext{
4 La Teoría del Estado Rentista explica que los estados cuyos ingresos derivan principalmente de una fuente externa en vez de impuestos, y en las poblaciones se benefician de la redistribución de la renta, existen pocas probabilidades de emergencia y desarrollo de movimientos sociales y políticos. BEBLAWI, Hazem, LUCIANI, Giacomo (Eds.), The Rentier State: Nation, State and the Integration of the Arab World, Croom Helm, London, 1987; CRYSTAL, Jill, Oil and Politics in the Gulf: rulers and merchants in Kuwait and Qatar, Cambridge University Press, Cambridge, 1990; GRAY, Matthew, "A Theory of 'Late Rentierism' in the Arab States of the Gulf", CIRS Occasional Paper n07, Doha, 2011; MAHDAVI, Hossein, The Patterns and Problems of Economic Development in Rentier States: the Case of Iran, University of London, London, 1970.

5 SALDAÑA Martín, Marta, Rentismo y Cultura Política en Emiratos Árabes Unidos: El caso de los estudiantes de la UAEU, Tesis doctoral, University of Exeter y Universidad Autónoma de Madrid, Julio 2014, pp. 87-95.

6 La proporción de extranjeros en Emiratos Árabes Unidos es del 88\%, en Qatar 85\%, Kuwait 68\%, Bahréin 54\%, Arabia Saudí $31 \%$ y Omán $30 \%$. Datos extraídos de los censos y compilados y estimados por el MIGRATION POLICY CENTER, European University Institute y el Gulf Research Center http://gulfmigration.eu/glmmdatabase/demographic-and-economic-module/ [Consultado el 15 de noviembre de 2016].
} 
Arabia Saudí, que fue oficialmente creado en 1932, los restantes estados obtuvieron su independencia formal del protectorado británico entre las décadas de los 60 y 70, por lo que las políticas de ciudadanía tuvieron que ser diseñadas a partir del establecimiento de nuevas fronteras y teniendo como referencia hitos históricos específicos para determinar quienes tenían derecho a acceder a esa ciudadanía. La mayoría de marcos legales para la determinación de la ciudadanía se establecieron al mismo tiempo que las constituciones o leyes básicas que configuraron los nuevos estados, si bien en algunos casos han sufrido modificaciones posteriores.

\subsection{Arabia Saudí}

El marco legal del sistema de ciudadanía en el reino de Arabia Saudí se estableció por la Orden Real no 8/20/5604 del 20 de octubre de 1954, y las disposiciones incluidas en la Ley Básica del Estado de 1992 y sus modificaciones hasta 20057. Los tres mecanismos para la obtención de ciudadanía son nacimiento, naturalización y descendencia. Según el artículo 4 de la orden, son ciudadanos saudíes "aquellos que adquirieran la nacionalidad otomana en el año 1914 siendo originario del territorio de Arabia Saudí"; "los ciudadanos otomanos nacidos en Arabia Saudí o residentes desde 1914 hasta el 30 de septiembre 1926 y que no hayan adquirido otra ciudadanía antes de esa fecha" y "los ciudadanos no otomanos que residían en Arabia Saudí desde 1914 hasta el 30 de septiembre 1926 y que no hayan adquirido otra ciudadanía antes de esa fecha". El artículo 7 establece el criterio del nacimiento a aquellos nacidos dentro o fuera del reino de padre saudí, o de madre saudí y padre desconocido, o de padres desconocidos pero dentro del reino.

Las provisiones para poder aplicar a la ciudadanía saudí, establecidas en el artículo 9, incluyen como mínimo haber residido legalmente en el país al menos por diez años y tener una ocupación necesaria para el país. Un sistema de puntos establece prioridades a aquellos con familiares saudíes, solicitantes con estudios superiores, etc. Los naturalizados saudíes también pueden transmitir la ciudadanía a sus esposas e hijos, de la misma manera que los ciudadanos varones por nacimiento. Por regla general, las mujeres saudíes casadas con no saudíes no transmiten la ciudadanía ni a sus cónyuges ni descendientes, pero el Ministerio del Interior puede otorgarla a los descendientes si se cumplen determinados requisitos de residencia permanente y buena conducta comprobable (artículo 8). La doble ciudadanía no está permitida sin consentimiento del Primer Ministro, y el ciudadano saudí que la obtuviera seguiría siendo considerado saudí a no ser que fuera despojado de la misma (artículo 11).

La obtención de otra ciudadanía es uno de los supuestos por los que se puede perder la saudí. Los otros incluyen haber trabajado para otro gobierno o fuerzas armadas sin consentimiento gubernamental; haberlo hecho para otro gobierno durante un conflicto armado con el reino saudí; o seguir trabajando para una organización internacional o gobierno extranjero a pesar que el gobierno saudí haya pedido su renuncia (artículo 13).

En el caso de los naturalizados, el Ministerio del Interior puede revocar la ciudadanía dentro de los cinco años de obtenida a aquellos que hayan sido sentenciados a más de un año de cárcel y aquellos que hayan "realizado o contribuido en cualquier operación que perturbe

7 Orden Real no 8/20/5604 de 1954 (22/2/1374 de la Hégira); Ley Básica de 1992 y modificaciones hasta 2005. 
la seguridad pública del reino" (artículo 21). La pérdida de ciudadanía conlleva también la de los dependientes y descendientes (artículo 23).

La ley saudí no establece diferencias en los derechos políticos entre los ciudadanos y los naturalizados con excepción de la composición de Consejo Consultivo y el Consejo de las Provincias, en las que los naturalizados no pueden ser miembros (Ley Básica, artículos 4 y 17).

\subsection{Kuwait}

El marco legal de la ciudadanía kuwaití está fijado en la Ley de Nacionalidad de 1959 y la Constitución de 1962, reinstaurada en $1992^{\circ}$. La ley establece que son ciudadanos kuwaitíes aquellos que hayan residido en territorio kuwaití antes de 1920 y que no hayan cambiado de residencia hasta la publicación de la ley, siendo estos considerados "kuwaitíes originales" (artículo 1). Aquellos nacidos de padre kuwaití o los nacidos dentro de Kuwait de padres desconocidos también obtienen directamente la ciudadanía kuwaití. Aquellos nacidos de madre kuwaití de padre desconocido o paternidad no legalmente reconocida también podrían ser naturalizados (artículo 3).

Entre los requisitos para la naturalización se incluye como mínimo haber residido legalmente en el país 20 años de manera consecutiva o 15 años si es ciudadano de otro estado árabe (artículo 4). También se estipula la necesidad de tener una profesión necesaria para el país y las cualificaciones adecuadas, incluyendo el conocimiento de la lengua árabe y la profesión del Islam por al menos cinco años. El Ministerio del Interior está capacitado para otorgar la ciudadanía en casos especiales a extranjeros que hayan servido al país, a aquellos árabes de otros países que hayan residido ininterrumpidamente en el país desde antes de 1945 y aquellos no árabes que lo hayan hecho desde antes de 1930 (artículo 5).

Los naturalizados deberán renunciar a su antigua ciudadanía dentro de los tres meses de obtenida, so pena de quedar sin efecto. También se revocaría en caso de apostasía, incluyendo a sus dependientes (artículo 4), si se obtiene otra ciudadanía (artículo 11), si se demuestra que se ha obtenido de forma fraudulenta, si dentro de los 15 años de obtenida la persona es convicta en relación a crímenes de honor u honestidad, o si dentro de los diez años de obtenida la persona es despedida de un empleo público por razones disciplinarias relacionadas con el honor y la honestidad (artículo 13).

Un ciudadano kuwaití podría perder la ciudadanía si sirve en las fuerzas armadas de otro país; si lo hace para otro gobierno durante un conflicto armado o que haya suspendido sus relaciones diplomáticas con el emirato; si trabaja en alguna asociación en el extranjero que amenace la estructura social y económica de Kuwait (artículo 14). Lo mismo es aplicable a aquellos naturalizados y sus dependientes.

La ciudadanía puede transferirse de marido a mujer extranjera, pero no a la inversa (artículo 9). La ley no prevé la transmisión de ciudadanía de una kuwaití casada con un extranjero a sus hijos.

\footnotetext{
8 Ley de Nacionalidad de 1959; Constitución de 1962, reinstaurada en 1992.
} 
La ley kuwaití establece diferentes derechos políticos a los naturalizados, que no pueden ser miembros de la Asamblea Nacional ni candidatos a la misma, y sólo pueden ejercer el voto tras 30 años de la naturalización (Ley artículo 6, Constitución, artículo 41).

\subsection{Omán}

El marco legal de la ciudadanía omaní es mucho más reciente que los anteriores casos, ya que se estableció con la Constitución de 1996, reformada en 2011, y el Decreto del Sultán no 38 de 2014, que implementó la Ley de Ciudadanía de Omán. La ley estipula que tanto hombres como mujeres extranjeros puede obtener la ciudadanía por casamiento si cumplen determinadas condiciones. Una mujer no omaní tiene que haberse casado con autorización previa del Ministerio del Interior y residir en Omán continuadamente al menos por diez años, tener un hijo de su marido omaní, hablar árabe y tener prueba escrita de haber renunciado a su anterior ciudadanía (artículo 16). En el caso del hombre, tiene que haber residido continuadamente al menos 20 años, o haber estado casado 15 años con una mujer omaní y tener un hijo de esa mujer (artículo 15). La doble ciudadanía no está permitida. La ley no prevé la transmisión de ciudadanía de una omaní casada con un extranjero a sus hijos.

En cuanto a derechos políticos, los ministros y viceministros, así como los miembros del Consejo Consultivo y del Consejo de Estado deber ser omaníes originales (Constitución, artículo 58).

\subsection{Bahréin}

Bahréin estableció su marco legal de ciudadanía en 1963 con el Acta de Ciudadanía, que fue modificada por la Ley no 10 de 1981, el Decreto Ley no 12 de 1989, y la reforma del artículo 10 de julio de 2014. También regula la ciudadanía la Constitución de 2002 con su reforma de $2012^{10}$. La ley de 1989 establece la descendencia, el nacimiento y la naturalización como los mecanismos para obtener la ciudadanía bahreiní. Como en los anteriores casos, es bahreiní quien nace en el país o en el extranjero de padre bahreiní o de madre bahreiní con padre desconocido o no legalmente relacionado con el padre (artículo 4).

Para naturalizarse bahreiní un residente legal tiene que pasar al menos 25 años consecutivos residiendo en el país, o 15 años si es ciudadano de otro país árabe, y tiene que poseer bienes inmuebles en el país (artículo 6). Sin embargo, la ciudadanía puede ser concedida también por orden real a cualquiera, árabe o no, que haya ofrecido buenos servicios al Estado (artículo 6). Una mujer puede obtener la ciudadanía bahreiní tras siete años de matrimonio con un ciudadano, pero el estado puede tanto reducir ese período de espera y también negar la ciudadanía a la mujer por razones de seguridad de Estado (artículo 7). Una mujer bahreiní perderá su ciudadanía si se casa con un extranjero y obtiene otra nacionalidad. La ley no prevé la transmisión de ciudadanía de una bahreiní casada con un no nacional a sus hijos.

Un naturalizado puede perder su ciudadanía si comete crímenes contra el honor y la honestidad dentro de los diez años de adquirida, aunque la pérdida no conlleva la de

\footnotetext{
9 Ley de ciudadanía de Omán (Decreto del Sultan No 38 de 2014); Constitución de 1996 reformada en 2011.

${ }^{10}$ Acta de Ciudadanía de 1963 y modificaciones hasta 2014; Constitución de 2002, reformada en 2012.
} 
los dependientes que la obtuvieron a través suyo (artículo 8). También sería revocada si realiza servicios militares para otro país, si ayuda o entra en servicio de un país enemigo y si causa perjuicios a la seguridad del Estado (artículo 10). Un bahreiní original puede perder su ciudadanía si adquiere otra ciudadanía o renuncia a la actual y se emite un decreto real para que le sea revocada (artículo 9). Además, la reforma del artículo 10 y 11 de la Ley de ciudadanía en julio de 2014 incluyó nuevos supuestos para la pérdida de ciudadanía, incluyendo deslealtad al gobierno e incumplimiento del deber de obediencia ${ }^{11}$.

Los naturalizados bahreiníes pueden ejercer derechos políticos, votar y ser miembros de ambas cámaras del parlamento, una vez superados los diez años de obtención de la ciudadanía (constitución, artículos 53 y 57).

\subsection{Qatar}

La ciudadanía se regula en Qatar con la Ley de Nacionalidad Qatarí no 2 de 1961, reformada por la ley no 38 de 2005, y con la constitución de 2003 ${ }^{12}$. La ley establece los criterios de residencia, descendencia, nacimiento y naturalización para obtener la ciudadanía. Son qataríes los residentes en el territorio nacional que mantuvieron su residencia regular desde 1930, los descendientes de qataríes nacidos dentro o fuera del país, y aquellos nacidos en Qatar de padres desconocidos (artículos 1 y 2 ).

Para ser naturalizado un residente extranjero debe pasar al menos y de manera continuada 25 años en el país, sin pasar más de dos meses cada año fuera del país, además de tener un medio legal de ingresos, hablar árabe y no haber sido convicto por ofensas contra la integridad y el honor (artículo 2). La naturalización puede ser extendida a sus hijos y esposa bajo decisión del Emir (artículo 4). También puede ser otorgada por decisión real a aquellos que hayan ofrecido un gran servicio al país o que tengan una particular habilidad necesitada en el país o estudiantes con capacidad científica. De manera excepcional, en estos casos pueden retener su ciudadanía original (artículo 6).

Las mujeres extranjeras casadas con varones qataríes pueden obtener la ciudadanía tras cinco años de matrimonio, y pasar la ciudadanía a sus hijos (artículo 8).

La ciudadanía qatarí puede ser revocada en el caso de que el ciudadano haya servido en las fuerzas armadas de otro país; haya sido empleado por un país en guerra con Qatar; se haya afiliado a cualquier autoridad, organización, asociación o grupo cuyo objetivo sea menoscabar la estructura política, económica o social del país; haya sido convicto por crímenes que contravienen la lealtad al Estado de Qatar o haya adquirido la ciudadanía de otro país (artículo 11).

Un naturalizado qatarí puede perder la ciudadanía si ha falseado la información para obtenerla; si comete crímenes contra el honor o la integridad; si es despedido de su trabajo por decisión disciplinaria relacionada con los motivos anteriores; o por haber estado fuera del

\footnotetext{
${ }^{11}$ HUMAN RIGHTS WATCH, "World Report 2015: Bahrain" 21 de agosto de 2014: https://www.hrw.org/worldreport/2015/country-chapters/bahrain [Consultado el 10 de noviembre de 2016]

12 Ley de Nacionalidad Qatarí no 2 de 1961, reformada por la ley no 38 de 2005; Constitución de 2003.
} 
país por más de un año sin justificación (artículo 12). La revocación de la ciudadanía no afecta a sus dependientes.

Las ciudadanas qataríes casadas con extranjeros no perderán la ciudadanía a no ser que se compruebe que hayan obtenido la ciudadanía de su cónyuge (artículo 10). Sus hijos tendrán prioridad entre los solicitantes de naturalización (artículo 2).

Los qataríes naturalizados no tienen derecho a trabajar en el sector público hasta haber cumplido cinco años de obtener la nacionalidad (artículo 16). Tampoco pueden ejercer el derecho a voto ni ser nominados a puestos electivos, formar parte del Consejo Consultivo, ni ser ministros, ya que dichos cargos están reservados a nacionales originales (ley, artículos 5 y 16, constitución, artículos 80 y 117).

\subsection{Emiratos Árabes Unidos}

El marco legal de la ciudadanía emiratí fue establecido por la Ley Federal de Nacionalidad y Pasaportes no 17 de 1972, enmendada por la ley no 10 de 1975, y por la constitución de 1971 reformada en $2009^{13}$. De acuerdo dichos textos, un árabe que estuviera establecido de manera continuada en cualquiera de los siete emiratos al menos desde 1925 y hasta el establecimiento de la ley es considerado ciudadano emiratí. También son ciudadanos los nacidos en Emiratos o en el extranjero de padre emiratí, y los nacidos de madre emiratí con padre sin relación legal con el hijo o con padre desconocido (artículo 2). Pueden obtener la ciudadanía emiratí los árabes de origen omaní, qatarí o bahreiní si han residido legalmente más de tres años en EAU, no han tenido antecedentes criminales y tienen un medio de vida; y también aquellos miembros de tribus de la península arábiga que hayan migrado de los países vecinos y que hayan residido continuadamente en Emiratos durante más de tres años (artículo 5). Las mujeres casadas con emiratíes pueden obtener la ciudadanía si renuncian a la previa.

La ciudadanía emiratí puede ser concedida a cualquier árabe competente que haya residido en el país por más de siete años, y también a cualquier otra persona que haya residido legalmente y continuadamente en el país desde 1940 (artículo 6, ley 1975 y artículo 7, ley 1972).

La ciudadanía puede ser revocada a personas que cometan o intenten cometer acciones que son consideradas peligrosas para la seguridad nacional. También si ha sido condenado repetidamente por crímenes contra el honor; si se ha encontrado falsificación en sus documentos para solicitar naturalización, y si reside sin justificación durante más de cuatro años fuera del país (artículo 16, ley 1975).

De acuerdo a las leyes federales de 1972 y 1975 las mujeres emiratíes casadas con extranjeros no pueden transmitir la ciudadanía a sus hijos, pero en diciembre de 2011, coincidiendo con la conmemoración del $40^{\circ}$ aniversario de la creación de los Emiratos Arabes Unidos, Sheikh Khalifa bin Zayed promulgó un decreto otorgando la ciudadanía a los hijos

${ }^{13}$ Ley Federal de Nacionalidad y Pasaportes no 17 de 1972, enmendada por la ley nº 10 de 1975; Constitución de 1971 reformada en 2009. 
de estas parejas mixtas, siendo hasta el momento el único Estado del CCG en oficializarlo ${ }^{14}$. No obstante, si bien en apenas dos meses después les fue concedida la ciudadanía a 1.117 hijos de mujeres emiratíes casadas con extranjeros ${ }^{15}$, todavía en la actualidad hay muchas solicitudes que no han sido atendidas.

Los derechos políticos de votar, ser elegido como miembro del Consejo Federal Nacional o ser nombrado Ministro están reservados únicamente a los ciudadanos originales emiratíes, y a los naturalizados de origen omaní, qatarí o bahreiní a partir de los siete años de obtenida la ciudadanía emiratí (artículo 13, ley 1972).

\section{Las políticas de ciudadanía y la consolidación política del CCG}

La sección anterior refleja lo restrictivas que son las políticas de ciudadanía en cuanto a naturalización de extranjeros y traspaso de derechos a familiares. Sin embargo, en parte ignorando dichas legislaciones, la ciudadanía era concedida con más facilidad durante los años de creación de los estados del Golfo, e incluso se invitaba a personas de países vecinos a mudarse a los nuevos estados a cambio de importantes beneficios sociales. Como se ha explicado más arriba, a medida que las poblaciones nacionales y la preocupación por la seguridad nacional y regional fueron creciendo, se fue restringiendo la concesión de ciudadanía y sus legislaciones se encuentran hoy entre las más restrictivas del mundo. La naturalización de extranjeros pasó a ser una cuestión controvertida y la vinculación del concepto de ciudadanía con el acceso a beneficios sociales un elemento fundamental para garantizar la estabilidad de los regímenes y el control de la población, incluso mucho antes de que la Primavera Árabe hiciera temblar la legitimidad del algunos de los estados del CCG.

\subsection{La naturalización política en Bahréin}

Es de destacar en primer lugar el caso de Bahréin, monarquía gobernada por la familia Al Khalifa, de confesión musulmana sunní, y con una población nacional que ha sido históricamente de mayoría musulmana shií16). Ello ha ocasionado numerosas demandas populares desde la década de los 70, y sobre todo tras el éxito de la Revolución Islámica de Irán en 1979, para una mayor participación de la comunidad shií en las decisiones políticas y en los beneficios distribuidos por el estado de bienestar. $Y$ es que tradicionalmente, los ciudadanos árabes shiíes (baharinah) y los shiíes de origen persa (ayam), han sido tratados como ciudadanos de segunda clase en Bahréin. La incorporación de estos grupos sociales a las ciudades y a otros sectores de la economía, y por tanto su acceso a la educación, no se ha visto acompañada de su integración en cargos públicos relevantes ni en las fuerzas armadas, siendo pocos los que alcanzan cargos de responsabilidad gubernamental ${ }^{17}$.

${ }^{14}$ SAJWANI, Huda "Citizenship law for Emirati women sets good example" en The National, 23 de diciembre de 2011: http://www.thenational.ae/thenationalconversation/comment/citizenship-law-for-emirati-women-setsgood-example [Consultado el 10 de noviembre de 2016].

15 MCGINLEY, Shane " 1,117 'foreign' children granted UAE citizenship" en Arabian Business, 20 de febrero de 2012: http://www.arabianbusiness.com/1-117-foreign-children-granted-uae-citizenship-446111.html [Consultado el 10 de noviembre de 2016].

${ }^{16}$ No existen estadísticas oficiales ya que representa un asunto de seguridad del estado. Aunque numerosas fuentes toman como válidos los porcentajes que van del 65 al 75\% de población shií, otras fuentes especializadas la citan en menos del 60\%, como en GENGLER, Justin, "Facts on the Ground: A Reliable Estimate of Bahrain's SunniShi'i Balance, and Evidence of Demographic Engineering", 5 de abril de 2011: http://bahrainipolitics.blogspot. qa/2011/04/facts-on-ground-reliable-estimate-of.html. [Consultado el 15 de noviembre de 2016].

17 SALDAÑA MARTIN, Marta, \& WILLIAMS, A., "Cambio y continuidad en el Bahréin post-Primavera Árabe", en 
La diferencia en los privilegios otorgados a la población sunní en detrimento de los shiíes ha sido profusamente documentada por organizaciones internacionales e investigadores, siendo notables las políticas utilizadas por el Estado para disminuir la presión demográfica y política de los shiíes sobre el gobierno. En primer lugar, cabe destacar la política de nacionalización de extranjeros de confesión sunní provenientes de países árabes y asiáticos, principalmente para servir en las fuerzas armadas y de seguridad. La denuncia formal y documentada de esta política fue conocida como "Bandargate"18, debido al nombre del autor del informe, Salah Al Bandar, presentado en septiembre de 2006 al gobierno de Bahréin, así como a delegaciones y medios de comunicación extranjeros. En el informe se denunciaba un plan gubernamental de cinco años diseñado para controlar políticamente al país a través de la nacionalización de sunníes para cambiar el balance demográfico sunni-shií y de la propagación de una ideología anti-shií. Al Bandar fue deportado del país tras la publicación del informe ${ }^{19}$.

Este caso también fue denunciado por el International Crisis Group en un informe de 2005 , en el que se mencionaba la cifra de entre 50.000 y 60.000 ciudadanías extendidas principalmente a jordanos, sirios y yemeníes, reclutados para servir en la policía y el ejército $^{20}$. El informe de la Comisión Independiente de Investigación sobre Bahréin (BICI), conocido popularmente como Informe Bassiouni, también se hizo eco de la cifra de 60.000 naturalizaciones otorgadas entre 2001 y 2007, que habían tenido un "efecto económico y social desastroso"21. Según el citado informe del Crisis Group, el gobierno bahreiní habría naturalizado también a 8.000 saudíes de la tribu Dawasir, originaria de Bahréin pero que han habitado durante décadas en la vecina Arabia Saudí. En este caso, los naturalizados no perdieron su condición de saudíes, siendo esto contrario a las dos leyes de ciudadanía, bahreiní y saudí, que prohíben la doble ciudadanía. Según la oposición shií, esta estrategia habría estado destinada a otorgar derechos políticos a saudíes para votar por los partidos progubernamentales en las elecciones de 2002 y 2006, y evitar así una victoria del principal partido opositor shií $A / W_{\text {efaq }}^{22}$. El mismo tipo de práctica ha sido denunciado en las elecciones de 2010 y 2014, al comprobarse durante los días electorales que gran cantidad de coches saudíes cruzaban el puente que une a los dos reinos para acercarse al más cercano centro de votación dentro de Bahréin ${ }^{23}$.

La segunda política de manipulación demográfica desarrollada por el gobierno es el diseño de un sistema de circunscripciones electorales que impida que la mayoría de la

GALINDO, A. \& WESTERN, W. (Ed.), Voces tramas y trayectorias: transiciones críticas en el Medio Oriente y norte de África, Universidad de Nuevo León y Universidad de Monterrey, Monterrey, 2016 (En imprenta).

${ }^{18}$ Al-BANDAR, Salah, "Al Bandar Report: Demographic engineering in Bahrain and mechanisms of exclusion", Bahrain Center for Human Rights, 30 de septiembre de 2006: http://www.bahrainrights.org/en/node/528 [Consultado el 15 de noviembre de 2016].

${ }^{19}$ SALDAÑA MARTIN, Marta, Bahrain: ¿un reino en busca de democracia?', Revista de Estudios Internacionales Mediterráneos, Vol. 5, 2008, pp. 49.

${ }^{20}$ INTERNATIONAL CRISIS GROUP, "Bahrain's Sectarian Challenge", Middle East Report N40, 6 de Mayo de 2005, p. 8: https://d2071andvip0wj.cloudfront.net/40-bahrain-s-sectarian-challenge.pdf [Consultado el 15 de noviembre de 2016].

${ }^{21}$ BICI, "Report of the Bahrain Independent Commission of Inquiry", 23 de noviembre de 2011, p. 110: http:// www.bici.org.bh/ [Consultado el 15 de noviembre de 2016].

22 INTERNATIONAL CRISIS GROUP, op. cit.

${ }^{23}$ Entrevista personal con observadores electorales de Transparency International Bahrain, Manama, noviembre de 2014. 
población shií pueda en ningún caso hacerse con la mayoría de la cámara de representantes ${ }^{24}$. Tras la instauración de la constitución en 2002, se han llevado a cabo cuatro elecciones generales $(2002,2006,2010$ y 2014) y unas complementarias en 2011. La oposición política, liderada por Al Wefaq, sólo participó en las de 2006 y 2010 , en la que obtuvo 16 y 18 de los 40 diputados respectivamente, a pesar de contar con la mayoría de los votos. En 2002 y 2014 Al Wefaq y otros partidos boicotearon las elecciones por su oposición al diseño de las circunscripciones. La reforma de los distritos en 2014 tampoco satisfizo a la oposición, que tras analizar la composición demográfica de las circunscripciones y compararlos con los resultados anteriores, llegaba a la conclusión de que en ningún caso se podrían obtener más de 18 diputados y decidieron continuar con el boicot ${ }^{25}$. En definitiva, la ingeniería electoral gubernamental, sumado a la naturalización de extranjeros suníes, diluyó cualquier oportunidad de la oposición de controlar la cámara, paliaron la los efectos del boicot electoral y evitaron la deslegitimación de los procesos electorales de 2011 y 2014.

\subsection{El castigo/recompensa tribal de Qatar}

El 27 de junio de 1995 el jeque Hamad bin Jalifa Al Thani se convertía en el Emir de Qatar tras deponer a su padre en un golpe de Estado incruento. Apenas unos meses después, en febrero de 1996, su tío y ex Ministro de Economía jefe de la Policía, el jeque Hamad bin Jassem, intentaba un contra golpe que terminó con él y otros 32 acusados en la cárcel con penas que iban desde algunos años a reclusión de por vida y 19 sentencias muerte, entre ellas la de un ciudadano saudí, Wabran al-Yami ${ }^{26}$. Las sospechas de que Arabia Saudí podría haber estado detrás de la intentona llevaron al Emir Hamad a tomar medidas severas contra el clan Ghufran de la tribu Al Murrah, al retirar por decreto real la ciudadanía qatarí a 5,226 miembros del clan, en abril de 2005. De acuerdo a la justificación oficial, las naturalizaciones qataríes habrían sido concedidas irregularmente por parte del anterior Ministro del Interior Hamad bin Nasser, ya que los miembros del clan conservaban aún su ciudadanía saudí. Al ser desprovistos de sus derechos fueron deportados hacia Arabia Saudí colectivamente, lo que generó protestas tanto de los afectados como de las autoridades saudíes ${ }^{27}$. Aunque la deportación no atrajo mayormente a los organismos de derechos humanos, sí generó debates sobre la utilización de la revocación de la ciudadanía por motivos políticos, penalizando a grandes grupos de población con lealtad tribal, algo que no está explicitado en la ley de ciudadanía, que estipula que la pérdida de ciudadanía provocada por la ejecución de un crimen no conlleva la de las sus familiares y dependientes. En este caso, por la participación en el intento de golpe de algunos de sus miembros, el castigo colectivo se hizo contra todo un clan tribal de la tribu Al Murrah, asentada en Qatar desde hacía 200 años, y de la que forma

${ }^{24}$ En las elecciones de 2010 la circunscripción más pequeña tenía 768 votantes (Southern Governorate, $6^{\circ}$ distrito, de mayoría sunní) mientras que la más grande tenía 16.216 votantes (Northern Governorate, $1^{\circ}$ distrito, de mayoría shií), ambas eligiendo un representante. VALERI, Marc, "Electoral Report: Bahrain/Parliamentary elections 2010", en OPEMAM Analysis, 26 de julio de 2011, p. 4: http://www.opemam.org/sites/default/files/ ER-Bahrain_parliamentary_2010.pdf [Consultado el 15 de noviembre de 2016].

${ }^{25}$ GENGLER, Justin, "Bahrain's New Electoral Districts: No Help for the Opposition; Bad for Troublesome Sunnis", en Religion and Politics in Bahrain, 13 de octubre de 2014: http://bahrainipolitics.blogspot.qa/2014/10/bahrainsnew-electoral-districts-no.html [Consultado el 15 de noviembre de 2016].

${ }^{26}$ BBC, "Life sentences for Qatari coup plotters", 29 de febrero de 2000: http://news.bbc.co.uk/2/hi/middle east/660887.stm; AL ARABIYA, "Qatar emir pardons Saudis involved in 1996 coup", 26 de mayo de 2010: https://www.alarabiya.net/articles/2010/05/26/109643.html [Consultado el 20 de noviembre de 2016].

27 AL HAKEEM, Mariam, "Thousands in Saudi Arabia after losing Qatari citizenship", en Gulf News, 3 de abril de 2005 : http://gulfnews.com/news/gulf/qatar/thousands-in-saudi-arabia-after-losing-qatari-citizenship-1.283103 [Consultado el 20 de noviembre de 2016]. 
parte casi la mitad de la población local28.

El castigo a grupos poblacionales pertenecientes a determinadas tribus también ha tenido una contrapartida en el caso qatarí. Cientos de varones provenientes de grupos tribales yemeníes fueron invitados por el jeque Hamad a sumarse a las fuerzas armadas y de seguridad del país a fines de los años 90, jurando lealtad al nuevo jefe de Estado. Muchos de esos emigrados obtuvieron la ciudadanía qatarí, pero la gran mayoría sigue manteniendo la yemení, aunque hayan abandonado el servicio militar y permanezcan en el país realizando otra actividad económica. Debido a los fuertes lazos de lealtad y fidelidad tribales demostrados por la población yemení, sus servicios han sido muy valorados, ya que mantienen, incluso tras su abdicación en 2013, la lealtad hacia el jeque Hamad²9.

\section{La securitización de las políticas de ciudadanía tras la Primavera Árabe}

Las revueltas iniciadas en Túnez en diciembre de 2010 se contagiaron a otros estados árabes incluidas las monarquías del Golfo, alentando a grupos pro-reforma y de oposición a exigir el reconocimiento de mayores derechos y participación política. Con las fuertes protestas en Bahréin y las algo menores en Omán entre febrero y marzo de 2011, la preocupación cundió entre las seis casas reales del CCG, ya que la caída de Ben Ali y Mubarak demostraba la imposibilidad de los regímenes de hacer frente a las masivas manifestaciones y ponía de relieve la vulnerabilidad de sus regímenes ${ }^{30}$. Dentro de la combinación de medidas redistributivas, electoralistas y represivas que pusieron en marcha para paliar los efectos desestabilizantes de las revueltas, los seis regímenes hicieron uso en modo variable de políticas de ciudadanía y naturalización, tanto como mecanismo de castigo a los opositores, como herramienta para reforzar la base social de sustento de los estados al eliminar cualquier elemento que atente contra la seguridad del Estado y la cohesión social. En este sentido, destacan los casos de Bahréin y Emiratos Árabes Unidos.

\subsection{El Estado de Seguridad Nacional y reforma legal en Bahréin}

En medio de las revueltas iniciadas en enero de 2011 el gobierno de Bahréin reaccionó utilizando diversos mecanismos para garantizar su estabilidad y la seguridad interna. Un día después de que las tropas saudíes ingresaran al emirato con el objetivo de proteger puntos estratégicos del reino, el 15 de marzo, y siguiendo la recomendación del Consejo Supremo de Defensa, se promulgaba el Decreto Real no 18 que declaraba el Estado de Seguridad Nacional durante tres meses. En su artículo 5, punto 12, la ley autoriza al Ministerio del Interior a "retirar la ciudadanía a los bahreiníes cuya presencia en el país sea un riesgo para el orden y seguridad pública, y a deportarlo del país o detenerlo"31.

En julio de 2013 la Asamblea Nacional y el Consejo Consultivo (ambas cámaras del

28 GHAFOUR, Abdul, "Talal Pleads the Case of Al-Murrah Tribe", en Arab News, 11 de junio de 2005: http://www. arabnews.com/node/268359 [Consultado el 20 de noviembre de 2016].

${ }^{29}$ Entrevista personal con miembro tribal yemení emigrado a Qatar por invitación del jeque Hamad bin Jalifa Al Thani, Doha, diciembre de 2014.

30 ZACCARA, Luciano; SALDAÑA MARTIN, Marta, "Cambio y estabilidad política en las monarquías del Golfo tras la Primavera Árabe", en Revista CIDOB d'Afers Internacionals n.109, p. 185.

${ }^{31}$ KINGDOM OF BAHRAIN, "Bahrain: Notification under Article 4 (3) Reference: C.N.261.2011.Treaties-5 (Depositary Notification) International Covenant on Civil and Political Rights New York", 2011, p. 3: https://treaties.un.org/ doc/Publication/CN/2011/CN.261.2011-Eng.pdf [Consultado el 10 de noviembre de 2016]. 
poder legislativo) promulgaban 22 recomendaciones adicionales a la Ley contra el Terrorismo promulgada en 2006. En las mismas se ampliaba la definición de terrorismo a aquellos actos considerados peligrosos para la seguridad nacional, incluyendo la libertad de expresión, asociación y reunión. Así, la ley reformada permite al gobierno incluir esos supuestos en los casos de revocación de la ciudadanía, principalmente a los disidentes políticos ${ }^{32}$.

Más aún, en febrero de 2014 el rey Hamad bin Jalifa reformaba la Ley de Ciudadanía de 1963, permitiendo que el Ministerio del Interior tenga la capacidad de revocar la ciudadanía de aquellos que "causen daño a los intereses del Estado, contravengan la lealtad al Estado o ayuden a un Estado hostil", así como a aquellos que incumplan el "deber de lealtad" al reino. Las asociaciones de derechos humanos destacan que 120 bahreiníes han perdido su ciudadanía desde la implementación de esas reformas hasta 201433. El gobierno usó esta normativa para penalizar cualquier tipo de disenso en los medios de comunicación y en las redes sociales, y sólo en enero de 2015 se contabilizaban 72 personas que perdieron su ciudadanía bajo esa ley, incluyendo cinco activistas vinculados a ISIS, pero también a conocidos periodistas, políticos y activistas por los derechos humanos, como el blogger Ali Abdulemam, el Dr. Ali Al-Dairi, fundador de Bahrain Mirror; el periodista Abbas Busafwan; el profesor universitario Masoud Jahromi; el ex diputado opositor Shaikh Hasan Sultan; y Sayed Ahmed Alwadaei, del Instituto Bahréin de Derechos y Democracia (BIRD) ${ }^{34}$.

Quizás el caso más resonado de aplicación de las penas de revocación de ciudadanía en Bahréin sea el del clérigo shií Sheikh Isa Qasim en junio de 2016, quien es considerado el líder en la sombra del partido opositor Al Wefaq, también disuelto el mismo mes. Detenido una semana antes, Qasim perdía su ciudadanía por decisión del Ministro del Interior, quedando a la espera de una sentencia sobre su posible deportación ${ }^{35}$.

El único desarrollo positivo alrededor de la ley de ciudadanía fue el incipiente debate, iniciado en 2015, sobre la posible extensión de los derechos ciudadanos a los hijos de mujeres bahreiníes casadas con extranjeros. Sin embargo, y a pesar de que el Consejo Supremo de la Mujer y el Comité de la Mujer y la Infancia de la Cámara de Representantes ha estado trabajando en el tema, hasta el momento no ha recibido una propuesta gubernamental para enmendar la ley de ciudadanía ${ }^{36}$.

32 ADHRB - BIRD - BCHR "Shattering the Façade. A Report on Bahrain's Implementation of the Bahrain Independent Commission of Inquiry (BICI) Recommendations Four Years On", Washington, 2015, p. 29: http://www. adhrb.org/2015/11/shattering-the-facade-a-report-on-bahrains-implementation-of-the-bahrain-independentcommission-of-inquiry-bici-four-years-on/ [Consultado el 10 de noviembre de 2016].

${ }^{33}$ HRW "Bahrain: Citizenship Rights Stripped Away" en Human Rights Watch, 21 de agosto de 2014 https:// www.hrw.org/news/2014/08/21/bahrain-citizenship-rights-stripped-away [Consultado el 10 de noviembre de 2016]; ADHRB "Stateless in Bahrain: 52 Nationalities Revoked" en Americans for Democracy \& Human Rights in Bahrain, 21 de noviembre de 2014 http://www.adhrb.org/2014/11/stateless-in-bahrain-52-nationalitiesrevoked/ [Consultado el 10 de noviembre de 2016].

${ }^{34}$ AL JAZEERA "Bahrain strips 72 of citizenship for 'harming' kingdom", 31 de enero de 2015: http://www. aljazeera.com/news/middleeast/2015/01/bahrain-strips-72-citizenship-harming-kingdom-150131140438495. html [Consultado el 10 de noviembre de 2016]; AMERICANS FOR DEMOCRACY \& HUMAN RIGHTS IN BAHRAIN "Bahrain Revokes the Citizenship of 72 Individuals", 2 de febrero de 2015: http://www.adhrb.org/2015/02/ bahrain-revokes-the-citizenship-of-72-individuals/ [Consultado el 10 de noviembre de 2016].

35 HUMAN RIGHTS WATCH, "Bahrain: Senior Cleric Faces Deportation", 22 de junio de 2016: https://www.hrw.org/ news/2016/06/22/bahrain-senior-cleric-faces-deportation [Consultado el 10 de noviembre de 2016].

${ }^{36}$ DT NEWS OF BAHRAIN, "Bahraini women to get the right of passing citizenship to children soon", 10 de Agosto de 2015: http://www.newsofbahrain.com/viewNews.php?ppId=4654\&TYPE=Posts\&pid=21\&MNU=2\&SUB=51 


\subsection{La represión política en Emiratos Árabes Unidos}

La Primavera Árabe tampoco dejó indiferente a EAU. A colación de la tardía convocatoria de elecciones para el Consejo Federal Nacional (CFN) en febrero de 2011, y el anuncio de que el colegio electoral sólo se extendería del $2.2 \%$ al $28 \%$ de los nacionales mayores de edad, un grupo de 133 nacionales presentaron una petición al Emir (conocida como la Petición del 3 de marzo) para que otorgase poder legislativo a la cámara y otorgase el derecho de voto a todos los ciudadanos. Entre los firmantes había ex-miembros del CFN y del gobierno, profesores universitarios, escritores, juristas, activistas políticos y de derechos humanos, así como miembros de la reducida sociedad civil emiratí, con distintas orientaciones políticas, e incluyendo a islamistas. Esta petición fue seguida de otra en abril presentada por las asociaciones de juristas y profesores, que también demandaba el sufragio universal ${ }^{37}$.

Ninguna de las peticiones recibió respuesta oficial más allá de la campaña iniciada por las autoridades para presentarlas ante la opinión pública como peticiones ilegitimas del sector islamista que anhelaba derrocar el régimen. Más aún, se puso en marcha la investigación y detención de los activistas con más proyección social. Entre ellos, cabe destacar el caso de los primeros detenidos por el Aparato de Seguridad Nacional y que son conocidos como los 'UAE 5'. El primero en ser arrestado fue Ahmed Mansoor (activista liberal), el 11 de abril de 2011, seguido por Nasser Bin Ghaith (profesor universitario islamista), Fahad Salim Dalk Al-Shehhi (liberal), Hassan Ali Al-Khamis (moderado), y Ahmed Abdulkhaleq al-Balushi (bloguero bidun con inclinación religiosa). Curiosamente, solamente Mansoor había participado en la redacción de la petición del 3 de marzo y la había firmado, mientras que el resto se limitaban a apoyar sus demandas y expresaban sus ideas abiertamente en las redes sociales. Todos ellos fueron arrestados en condiciones poco ortodoxas y vieron sus pasaportes confiscados durante el proceso de detención. Además, se puso en marcha una campaña de desprestigio en contra de los peticionistas, que les presentaba como traidores a la nación, agentes extranjeros, criticaba sus orígenes étnicos y les asociaba con organizaciones islamistas radicales. Tras ocho meses de prisión preventiva, durante los cuales fueron sometidos a confinamiento solitario y tortura psicológica y física, Masoor fue sentenciado a tres años y los otros cuatro a dos años de cárcel acusados de romper las leyes y perpetrar actos contra la seguridad del Estado, alterar el orden público, oponerse al sistema de gobierno e insultar al presidente ${ }^{38}$. Sin embargo, en diciembre del mismo año, y coincidiendo con el 40 aniversario del establecimiento de la Federación de EAU, el presidente emitió un decreto perdonando la condena de cárcel a los cinco, pero que no retiraba los cargos ni suponía la devolución de sus pasaportes. Además, a Ahmed Abdulkhaleq le fueron retirados los documentos de residencia, le fue dado un pasaporte de las Islas Comores, y fue deportado a Tailandia ${ }^{39}$.

La campaña de detenciones se centró entonces contra activistas con vínculos con la asociación islamista al-Islah (y la paralela Da'wat al-Islah) y se comenzaron a dar detenciones

[Consultado el 10 de noviembre de 2016].

37 SALDAÑA MARTÍN, Marta, Rentismo y Cultura Política en Emiratos Árabes Unidos: El caso de los estudiantes de la UAEU, Tesis doctoral, University of Exeter y Universidad Autónoma de Madrid, Julio 2014, pp. 176-187.

${ }^{38}$ El artículo 176 del Código Penal Federal (Ley Federal 3/1987, y sus modificaciones) permite sentencias de prisión de hasta cinco años a "cualquiera que insulte públicamente al presidente, o al emblema o la bandera nacional". El artículo 8 amplía estas provisiones al vice-presidente, a los miembros del Consejo Supremo Federal, y a otros.

39 Más tarde le fue concedido el asilo político en Canadá. Entrevista personal con Ahmed Mansoor, Dubai, UAE (Abril 2014). 
indiscriminadas bajo acusaciones de fundar, organizar y administrar una organización con el objetivo de derrocar al gobierno. A un primer grupo de siete personas, algunos de los cuales eran firmantes de la petición del 3 de marzo, se les retiró la nacionalidad que les había sido otorgada con posterioridad al establecimiento del Estado moderno, reflejando la vulnerabilidad del estatus de los emiratíes naturalizados. Eventualmente, hubo más de 100 detenidos. El régimen estaba enviando un claro mensaje a potenciales opositores políticos de que ponían en riesgo su ciudadanía, así como los beneficios asociados ${ }^{40}$.

Más aún, el decreto ley sobre ciber crímenes emitido en noviembre de $2012^{41}$, y que reemplazaba al de 2006, criminaliza un amplio abanico de actividades aceptadas internacionalmente y prevé castigos por ofender al Estado, a sus dirigentes, sus símbolos, o por insultar al Islam u otras religiones. Así, cualquier demanda de reforma del sistema político puede ser penalizada con cadena perpetua, lo cual ha logrado acallar las voces de aquellos que anhelan cambios en el país.

La implementación a rajatabla de las nuevas leyes de seguridad implicó la retirada de pasaporte y revocación de nacionalidad a decenas de emiratíes naturalizados desde entonces. Por ejemplo, en marzo de 201230 sirios naturalizados fueron deportados del país sin su ciudadanía emiratín ${ }^{2}$, y según algunas fuentes, las deportaciones y revocaciones de ciudadanía habrían Ilegado a cientos hasta la actualidad. El último resonado caso es el de Mohammed Abdulraziq al-Siddiq, quien fue detenido en 2013 y se resistió a la petición de que solicitara una nueva ciudadanía. Unos meses después fue sentenciado a diez años de prisión en el juicio contra los 'EAU 94'. Tras serle revocada su ciudadanía, sus tres hijos, de entre 23 y 29 años, también perdieron la suya, y les era informado en marzo de 2016 que deberían buscar otra ciudadanía. En este caso, Siddiq, considerado por los organismos de derechos humanos como un prisionero político, era ciudadano por ley y no por naturalización, nacido en Emiratos, y portador de una sola ciudadanía. Lo mismo se aplicaba a sus hijos, que al perder la ciudadanía emiratí quedaban como apátridas, lo que contraviene la propia legislación emiratí3 ${ }^{3}$. Ante la amenaza que las peticiones de reforma representaban, la pérdida de derechos económicos y políticos, a través de la revocación de la ciudadanía se convirtió en la herramienta principal del estado para silenciar de la oposición política.

\subsection{La naturalización de bahreiníes en Qatar}

La naturalización de extranjeros como medida para incrementar la población nacional de determinados grupos tribales o religiosos, ya sea con objetivos electoralistas o para perpetuar una identidad determinada del estado, también ha generado disputas internas entre los estados miembros del CCG, sobre todo a partir de las revueltas primaverales. De particular interés son la controversia por la nacionalización concedida por Qatar a ciudadanos bahreiníes de confesión sunní, y la práctica de doble ciudadanía utilizada por saudíes con respecto a Kuwait, Bahréin y Qatar.

40 SALDAÑA MARTÍN, Marta, 2014, Op. cit., pp. 176-187.

${ }^{41}$ Decreto Ley 5/2012.

42 GULF STATES NEWSLETTER, "UAE expulsions", Volume 36, Issue 919, 8 March 2012, p. 1-3.

43 INTERNATIONAL CENTRE FOR JUSTICE AND HUMAN RIGHTS, "The United Arab Emirates denies the unlawfulness of the al-Siddiq siblings' citizenship revocation", 10 de octubre de 2016: http://www.ic4jhr.org/en/activites/ statements/545-uae-the-united-arab-emirates-denies-the-unlawfulness-of-the-al-siddiq-siblings\%E2\%80\%99citizenship-revocation-2.html [Consultado el 21 de noviembre de 2016]. 
En 2014 estalló la polémica por la denuncia del gobierno de Bahréin de que Qatar estaba interfiriendo en los asuntos internos de la isla al ofrecer ciudadanía y beneficios económicos a ciudadanos bahreiníes de filiación sunní. En lo que resulta una paradoja, el Ministro de Asuntos Exteriores de Bahréin, Khalid Bin Ahmad Al Khalifa, denunció que Qatar estaba "discriminando a los ciudadanos de Bahréin sobre una base sectaria", afirmando que "si el bahreiní es sunni y miembro de una tribu árabe, la puerta está abierta, pero si es shií, la puerta está cerrada"44. Debido a la sensibilidad del balance demográfico sunni-shií en Bahréin, cualquier medida que implique la pérdida de ciudadanos sunníes es considerada una amenaza a la estabilidad de los Al Khalifa en el poder. Las autoridades de Qatar reconocieron que esta política llevaba tiempo ejecutándose, debido a que el Estado intentaba recuperar familias originales qataríes que habían migrado a Bahréin en el siglo pasado. El ex Ministro de Justicia bahreiní? Najeeb Al Nuaimi se quejaba, sin embargo, de que los procedimientos se habían modificado. Mientras que anteriormente era necesario vivir al menos tres años en Qatar tras renunciar a la ciudadanía bahreiní para ser naturalizado, en el momento de la denuncia se concedía la nacionalidad en 24 horas $^{45}$.

La disputa sobre la naturalización sobrevino en medio de la crisis diplomática que se había desatado en enero de 2014 entre Qatar y sus socios del CCG, Arabia Saudí, Emiratos Árabes Unidos y Bahréin, debido -oficialmente- a la interferencia qatarí en los asuntos internos de los otros estados, y a la reticencia qatarí de firmar los acuerdos de seguridad interna del CCG, lo que generó la retirada de los tres embajadores de Doha. Sin que fueran publicadas cifras concretas sobre la cantidad de personas o familias que hubieran estado involucradas en la naturalización, la controversia se dio por zanjada con el anuncio oficial por parte de Qatar de que dejarían de ofrecer la ciudadanía a bahreiníes ${ }^{46}$. El entendimiento llegó en el mismo momento de la cumbre del CCG en Doha en la que se solventó el conflicto diplomático, por lo que se demuestra cuán crucial es para la supervivencia de los regímenes del Golfo las políticas de ciudadanía.

\subsection{Saudíes con doble ciudadanía}

Aunque la mayoría de las leyes de ciudadanía del CCG prohíbe expresamente la doble ciudadanía, incluyendo la de los propios países del Golfo, el mantenimiento de ambas, en caso de familias o individuos cuyos orígenes tribales es transfronterizo, ha sido una práctica habitual, y que ha generado numerosas protestas oficiales. El caso más notable es el de ciudadanos con doble ciudadanía saudí-kuwaití y saudí-bahreiní.

De acuerdo a datos publicados en 2014 la cantidad de aquellos poseedores de la nacionalidad saudí y kuwaití sería de 432.000 individuos, mucho mayor de la que se especulaba,

44 TOUMI, Habib, "Bahrain accuses Qatar of 'sectarian naturalisation'", en Gulf News, 13 de julio de 1914: http:// gulfnews.com/news/gulf/qatar/bahrain-accuses-qatar-of-sectarian-naturalisation-1.1359196 [Consultado el 21 de noviembre de 2016].

${ }^{45}$ WINDRUM, Elysia, "Bahrain: Qatar compromising national security by wooing citizens", en Doha News, 10 de Agosto de 2014: http://dohanews.co/gcc-tensions-qatar-reaches-bahrainis-nationality-swap/ [Consultado el 21 de noviembre de 2016].

${ }^{46}$ AL-SUHAYMI, "Qatar no longer offering citizenship to Bahraini nationals: Bahrain interior minister", en Al Shark al Awsat, 19 de noviembre de 2014: http://english.aawsat.com/2014/11/article55338696/qatar-no-longeroffering-citizenship-to-bahraini-nationals-bahrain-interior-minister [Consultado el 21 de noviembre de 2016]. 
y la mayoría de ellos sin el consentimiento o conocimiento de las autoridades de ambos países ${ }^{47}$. La controversia ya se había iniciado con anterioridad, y ante la comprobación por parte de observadores electorales kuwaitíes y periodistas, de una gran afluencia de viajeros saudíes, tanto en coche como en avión, que acudían a Kuwait durante los fines de semana electorales. Estas personas, con plenos derechos políticos en el emirato, habrían votado por candidatos tribales afines ${ }^{48}$. Debido a la ilegalidad de esta situación, ya que ambas legislaciones impiden con excepciones la doble nacionalidad, el gobierno kuwaití ha implementado una dura política para exigir la renuncia a alguna de las dos ciudadanías, so pena de serle revocada la kuwaití. La última decisión había sido tomada en agosto de 2016, cuando 29 ciudadanos kuwaitíes con la segunda nacionalidad saudí y qatarí fueron desnaturalizados al optar por la ciudadanía extranjera ${ }^{49}$.

En el caso de ciudadanos con doble ciudadanía saudí-bahreiní, y como se mencionó en apartados anteriores, se habría alentado a miembros saudíes de la tribu pro-gubernamental Al Dosari a cruzar la frontera y votar en las elecciones de Bahréin, sobre todo a partir de 2014, cuando las bajas tasas de participación hacían peligrar la legitimidad de los comicios. Esta práctica ha sido denunciada por la oposición, sin que las autoridades saudíes o bahreiníes reaccionaran al respecto. Sin embargo, el gobierno bahreiní sí habría reaccionado con respecto al uso de la doble ciudadanía en los casos en las que sus beneficiarios "usaron su estatuto para protegerse contra acciones legales tras haber cometido acciones que perjudiquen la paz y la seguridad y que son punibles por ley"50, indudablemente otra paradoja del caso bahreiní. También ha sido el caso de tres candidatos con doble nacionalidad que fueron rechazados en las elecciones generales de Bahréin de 2014, debido a que la constitución y ley electoral solo admite a candidatos bahreiníes originales o tras diez años de haber sido naturalizados. Sin embargo, algunos candidatos excluidos en 2014, como Sharekh Al Dosari, había ya sido candidato en anteriores elecciones sin que hubiera generado ninguna controversia ${ }^{51}$.

\subsection{El afianzamiento de las medidas de seguridad}

Las securitización de las políticas de naturalización se extendió también en la mayoría de los casos del Golfo a los permisos de residencia otorgados a no nacionales como consecuencia de la efervescencia política generada por la Primavera Árabe y el temor al contagio. Los principales grupos nacionales que han sufrido por el cambio en la concesión de visados de trabajo han sido los residentes árabes provenientes de países que han sufrido revueltas, como Egipto, Siria o Yemen. Especial hincapié, sobre todo desde el empeoramiento de las relaciones entre Irán y el CCG, y en particular con Arabia Saudí, se ha hecho respecto a residentes iraníes o de confesión shií, aunque no exista reconocimiento oficial de esta política. En Emiratos Árabes

47 TOUMI, Habib, "Kuwait to summon dual nationality holders", en Gulf News, 27 de julio de 2014: http://gulfnews. $\mathrm{com} /$ news/gulf/kuwait/kuwait-to-summon-dual-nationality-holders-1.1364459 [Consultado el 21 de noviembre de 2016].

48 Entrevista personal con observadores electorales y periodistas en Kuwait, Febrero de 2012.

49 ARAB TIMES, "29 Dual-Nationality Citizens Renounce Kuwaiti Citizenship - Hold on to Saudi, Qatari Nationalities", 20 de agosto de 2016: http://www.arabtimesonline.com/news/29-dual-nationality-citizens-renounce-kuwaiticitizenship-hold-saudi-qatari-nationalities/ [Consultado el 21 de noviembre de 2016].

50 TOUMI, Habib, "Bahrain urges dual citizenship holders to verify legal status", en Gulf News, 8 de abril de 2012: http://gulfnews.com/news/gulf/bahrain/bahrain-urges-dual-citizenship-holders-to-verify-legalstatus-1.1005615 [Consultado el 21 de noviembre de 2016].

${ }^{51}$ ARAB NEWS, "Manama bans Saudi-Bahrainis from elections", 13 de noviembre de 2014: http://www.arabnews. com/saudi-arabia/news/659346 [Consultado el 21 de noviembre de 2016]. 
era ya una norma para ciertas universidades no contratar a profesores con las mencionadas características ya en $2012^{52}$. La misma restricción respecto a residentes shiíes o iraníes, o de académicos que puedan generar polémicas o protestas de estados aliados parece estar vigente en Qatar desde 2014. Al menos cuatro investigadores/profesores habrían sufrido desde entonces problemas en la renovación de los visados de trabajo al no pasar el veto del Ministerio del Interior, y a pesar de haber residido y trabajando en el país y en instituciones públicas qataríes durante los años precedentes ${ }^{53}$.

\section{Conclusiones}

Las políticas de ciudadanía han sido uno de los pilares de la construcción del Estado y la identidad en las monarquías del Golfo. También han sido una de las herramientas de consolidación de los regímenes vigentes y de control social de la población, toda vez que la ciudadanía ha conllevado, en la mayoría de los casos, beneficios sociales y económicos derivados del estado de bienestar rentista.

La historia política reciente de estos estados demuestra que la evolución de las políticas de ciudadanía y naturalización ha dependido de los beneficios o perjuicios políticos que las mismas podrían ocasionar al Estado y las élites gobernantes. Sobre todo a partir de la Primavera Árabe, en la que las movilizaciones masivas afectaron incluso a los ricos estados del CCG, y en donde la legitimidad política de los gobernantes fue puesta en cuestión, el uso político de la ciudadanía/naturalización fue algo común a las seis monarquías, dejando en claro la sensibilidad del tema y la imposibilidad de que se produzcan cambios inclusivos significativos en el futuro cercano.

Al contrario, los incidentes detallados en relación a naturalizaciones colectivas selectivas, junto a los casos de revocación de ciudadanías, colectiva o individual, parecen confirmar la idea de que en este grupo de países la ciudadanía no es un derecho que pertenece a cada uno de los individuos sino una gracia concedida a discreción por las autoridades en base a criterios étnicos, religiosos, políticos e ideológicos. Más aún, el mensaje evidente que los últimos años sugieren es el de que la ciudadanía dentro del contexto del Consejo de Cooperación del Golfo, es revocable en cualquier momento, sea el ciudadano original o naturalizado.

Según la realidad social de cada país, algunos estados han puesto el énfasis en la revocación de ciudadanía o la confiscación de pasaportes de los opositores políticos, otros combinan estas políticas con las de nacionalización de extranjeros para modificar la balanza demográfica, y todos ellos están respondiendo en mayor o menor medida a las demandas de naturalización de los hijos de ciudadanas mujeres.

Sin embargo, esta concepción no es el resultado de la Primavera Árabe, sino que está en el centro de las políticas de ciudadanía diseñadas en las décadas precedentes. Como se

\footnotetext{
52 Entrevista con el director de un instituto de investigación de la Universidad Khalifa en Abu Dhabi, Emiratos Árabes Unidos, en febrero de 2012.

${ }^{53}$ Entrevistas con profesores e investigadores de la Universidad de Qatar, Georgetown University in Qatar y King's College in Qatar, entre septiembre de 2015 y noviembre de 2016. Estos casos no ha sido reflejados hasta el momento en la prensa especializada, por lo que se prefiere mantener el anonimato de los afectados y las fuentes.
} 
pudo comprobar a lo largo de estas páginas, han sido pocas las modificaciones a las leyes previas a la Primavera Árabe, con la clara excepción de Bahréin. En la mayoría de los casos sólo cambió la interpretación de los supuestos por los que se puede revocar la ciudadanía, amparado en las nuevas leyes de emergencia o anti-terroristas. Por el contrario, algunas modificaciones parecen haber ido en sentido inclusivo, como la modificación de los supuestos de naturalización de hijos de mujer emiratí casada con no emiratí, y que parece estar alentando a otros estados como Arabia Saudí ${ }^{4}$ y Bahréin a seguir los pasos, algo que sin duda podría ser interpretado como compensación por las otras políticas restrictivas implementadas en cuanto a las naturalizaciones.

\section{Bibliografía}

ADHRB - BIRD - BCHR "Shattering the Façade. A Report on Bahrain's Implementation of the Bahrain Independent Commission of Inquiry (BICI) Recommendations Four Years On", Washington, 2015, p. 29: http://www.adhrb.org/2015/11/shattering-the-facade-a-report-on-bahrainsimplementation-of-the-bahrain-independent-commission-of-inquiry-bici-four-years-on/ [Consultado el 10 de noviembre de 2016].

AGIUS, Dionisius, "The Rashayda: Ethnic identity and dhow activity in Suakin on the Red Sea coast" en Northeast African Studies, no12/1, 2012, pp. 169-216.

AL ARABIYA, "Qatar emir pardons Saudis involved in 1996 coup", 26 de mayo de 2010: https://www. alarabiya.net/articles/2010/05/26/109643.html [Consultado el 20 de noviembre de 2016].

AL-BANDAR, Salah, "Al Bandar Report: Demographic engineering in Bahrain and mechanisms of exclusion", Bahrain Center for Human Rights, 30 de septiembre de 2006: http://www.bahrainrights.org/en/ node/528 [Consultado el 15 de noviembre de 2016].

AL HAKEEM, Mariam, "Thousands in Saudi Arabia after losing Qatari citizenship", en Gulf News, 3 de abril de 2005: http://gulfnews.com/news/gulf/qatar/thousands-in-saudi-arabia-after-losingqatari-citizenship-1.283103 [Consultado el 20 de noviembre de 2016].

AL JAZEERA "Bahrain strips 72 of citizenship for 'harming' kingdom", 31 de enero de 2015: http:// www.aljazeera.com/news/middleeast/2015/01/bahrain-strips-72-citizenship-harmingkingdom-150131140438495.html [Consultado el 10 de noviembre de 2016];

AL SAGHEER, Mariam, "Nationality for children of non-Saudi fathers under Shoura study", en Saudi Gazette, 12 de octubre de 2016: http://saudigazette.com.sa/saudi-arabia/nationality-childrennon-saudi-fathers-shoura-study/ [Consultado el 21 de noviembre de 2016].

AL-SUHAYMI, "Qatar no longer offering citizenship to Bahraini nationals: Bahrain interior minister", en Al Shark al Awsat, 19 de noviembre de 2014: http://english.aawsat.com/2014/11/ article55338696/qatar-no-longer-offering-citizenship-to-bahraini-nationals-bahrain-interiorminister [Consultado el 21 de noviembre de 2016].

AMERICANS FOR DEMOCRACY \& HUMAN RIGHTS IN BAHRAIN "Bahrain Revokes the Citizenship of 72 Individuals", 2 de febrero de 2015: http://www.adhrb.org/2015/02/bahrain-revokes-thecitizenship-of-72-individuals/ [Consultado el 10 de noviembre de 2016].

AMERICANS FOR DEMOCRACY \& HUMAN RIGHTS IN BAHRAIN "Stateless in Bahrain: 52 Nationalities Revoked", 21 de noviembre de 2014: http://www.adhrb.org/2014/11/stateless-in-bahrain-52nationalities-revoked/ [Consultado el 10 de noviembre de 2016].

ANANI, Ahmad, WHITTINGHAM, Ken, The Early History of the Gulf Arabs, Longman, Londres y Nueva York, 1986.

${ }^{54}$ AL SAGHEER, Mariam, "Nationality for children of non-Saudi fathers under Shoura study", en Saudi Gazette, 12 de octubre de 2016: http://saudigazette.com.sa/saudi-arabia/nationality-children-non-saudi-fathers-shourastudy/ [Consultado el 21 de noviembre de 2016]. 
ARAB NEWS, "Manama bans Saudi-Bahrainis from elections", 13 de noviembre de 2014: http://www. arabnews.com/saudi-arabia/news/659346 [Consultado el 21 de noviembre de 2016].

ARAB TIMES, "29 Dual-Nationality Citizens Renounce Kuwaiti Citizenship - Hold on to Saudi, Qatari Nationalities", 20 de agosto de 2016: http://www.arabtimesonline.com/news/29-dualnationality-citizens-renounce-kuwaiti-citizenship-hold-saudi-qatari-nationalities/ [Consultado el 21 de noviembre de 2016].

BBC, "Life sentences for Qatari coup plotters", 29 de febrero de 2000: http://news.bbc.co.uk/2/hi/ middle_east/660887.stm

BEBLAWI, Hazem, LUCIANI, Giacomo (Eds.), The Rentier State: Nation, State and the Integration of the Arab World, Croom Helm, London, 1987.

BICI, "Report of the Bahrain Independent Commission of Inquiry", 23 de noviembre de 2011, p. 110: http://www.bici.org.bh/ [Consultado el 15 de noviembre de 2016].

CRYSTAL, Jill, Oil and Politics in the Gulf: rulers and merchants in Kuwait and Qatar, Cambridge University Press, Cambridge, 1990.

DT NEWS OF BAHRAIN, "Bahraini women to get the right of passing citizenship to children soon", 10 de Agosto de 2015: http://www.newsofbahrain.com/viewNews. php?ppId $=4654 \&$ TYPE $=$ Posts\&pid $=21 \& M N U=2 \& S U B=51$ [Consultado el 10 de noviembre de 2016].

GENGLER, Justin, "Bahrain's New Electoral Districts: No Help for the Opposition; Bad for Troublesome Sunnis", en Religion and Politics in Bahrain, 13 de octubre de 2014: http://bahrainipolitics. blogspot.qa/2014/10/bahrains-new-electoral-districts-no.html [Consultado el 15 de noviembre de 2016].

GENGLER, Justin, "Facts on the Ground: A Reliable Estimate of Bahrain's Sunni-Shi'i Balance, and Evidence of Demographic Engineering", 5 de abril de 2011: http://bahrainipolitics.blogspot. qa/2011/04/facts-on-ground-reliable-estimate-of.html. [Consultado el 15 de noviembre de 2016].

GHAFOUR, Abdul, "Talal Pleads the Case of Al-Murrah Tribe", en Arab News, 11 de junio de 2005: http:// www.arabnews.com/node/268359 [Consultado el 20 de noviembre de 2016].

GRAY, Matthew, "A Theory of 'Late Rentierism' in the Arab States of the Gulf", CIRS Occasional Paper n07, Doha, 2011.

GULF STATES NEWSLETTER, "UAE expulsions", Volume 36, Issue 919, 8 March 2012, p. 1-3.

HUMAN RIGHTS WATCH, "Bahrain: Senior Cleric Faces Deportation", 22 de junio de 2016: https:// www.hrw.org/news/2016/06/22/bahrain-senior-cleric-faces-deportation [Consultado el 10 de noviembre de 2016].

HUMAN RIGHTS WATCH "World Report 2015: Bahrain" 21 de agosto de 2014: https://www.hrw.org/ world-report/2015/country-chapters/bahrain [Consultado el 10 de noviembre de 2016].

HUMAN RIGHTS WATCH "Bahrain: Citizenship Rights Stripped Away", 21 de agosto de 2014: https:// www.hrw.org/news/2014/08/21/bahrain-citizenship-rights-stripped-away [Consultado el 10 de noviembre de 2016].

INTERNATIONAL CENTRE FOR JUSTICE AND HUMAN RIGHTS, "The United Arab Emirates denies the unlawfulness of the al-Siddiq siblings' citizenship revocation", 10 de octubre de 2016: http:// www.ic4jhr.org/en/activites/statements/545-uae-the-united-arab-emirates-denies-theunlawfulness-of-the-al-siddiq-siblings\%E2\%80\%99-citizenship-revocation-2.html [Consultado el 21 de noviembre de 2016].

INTERNATIONAL CRISIS GROUP, "Bahrain's Sectarian Challenge", Middle East Report N40, 6 May 2005, p. 8: https://d2071andvip0wj.cloudfront.net/40-bahrain-s-sectarian-challenge.pdf [Consultado el 15 de noviembre de 2016].

KINGDOM OF BAHRAIN, "Bahrain: Notification under Article 4 (3) Reference: C.N.261.2011.Treaties-5 (Depositary Notification) International Covenant on Civil and Political Rights New York", 2011, p. 3: https://treaties.un.org/doc/Publication/CN/2011/CN.261.2011-Eng.pdf [Consultado el 10 de noviembre de 2016]. 
MCGINLEY, Shane "1,117 'foreign' children granted UAE citizenship" en Arabian Business, 20 de febrero de 2012: http://www.arabianbusiness.com/1-117-foreign-children-granted-uaecitizenship-446111.html [Consultado el 10 de noviembre de 2016].

MAHDAVI, Hossein, The Patterns and Problems of Economic Development in Rentier States: the Case of Iran, University of London, London, 1970.

MIGRATION POLICY CENTER, European University Institute y el Gulf Research Center http:// gulfmigration.eu/glmm-database/demographic-and-economic-module/ [Consultado el 10 de noviembre de 2016]

PETERSON, John E., "Oman's diverse society: Southern Oman" en The Middle East Journal, no 58/2, 2004, pp. 254-269.

POTTS, Daniel T., Ancient Magan: The Secrets of Tell Abraq, Trident, London, 2000.

SAJWANI, Huda "Citizenship law for Emirati women sets good example" en The National, 23 de diciembre de 2011: http://www.thenational.ae/thenationalconversation/comment/citizenship-law-foremirati-women-sets-good-example [Consultado el 10 de noviembre de 2016].

SALDAÑA MARTIN, Marta, \& WILLIAMS, A., "Cambio y continuidad en el Bahréin post-Primavera Árabe", en GALINDO, A. \& WESTERN, W. (Ed.), Voces tramas y trayectorias: transiciones críticas en el Medio Oriente y norte de África, Universidad de Nuevo León y Universidad de Monterrey, Monterrey, 2016 (En imprenta).

SALDAÑA MARTIN, Marta, Rentismo y Cultura Política en Emiratos Árabes Unidos: El caso de los estudiantes de la UAEU, Tesis doctoral, University of Exeter y Universidad Autónoma de Madrid, Julio 2014.

SALDAÑA MARTIN, Marta, Bahrain: ¿un reino en busca de democracia?', Revista de Estudios Internacionales Mediterráneos, Vol. 5, 2008, pp. 49.

TOUMI, Habib, "Kuwait to summon dual nationality holders", en Gulf News, 27 de julio de 2014: http://gulfnews.com/news/gulf/kuwait/kuwait-to-summon-dual-nationality-holders-1.1364459 [Consultado el 21 de noviembre de 2016].

TOUMI, Habib, "Bahrain accuses Qatar of 'sectarian naturalisation'", en Gulf News, 13 de julio de 1914: http://gulfnews.com/news/gulf/qatar/bahrain-accuses-qatar-of-sectariannaturalisation-1.1359196 [Consultado el 21 de noviembre de 2016].

TOUMI, Habib, "Bahrain urges dual citizenship holders to verify legal status", en Gulf News, 8 de abril de 2012: http://gulfnews.com/news/gulf/bahrain/bahrain-urges-dual-citizenship-holders-toverify-legal-status-1.1005615 [Consultado el 21 de noviembre de 2016].

VALERI, Marc, "Electoral Report: Bahrain/Parliamentary elections 2010", en OPEMAM Analysis, 26 de julio de 2011, p. 4: http://www.opemam.org/sites/default/files/ER-Bahrain_parliamentary_2010.pdf [Consultado el 15 de noviembre de 2016].

WINDRUM, Elysia, "Bahrain: Qatar compromising national security by wooing citizens", en Doha News, 10 de Agosto de 2014: http://dohanews.co/gcc-tensions-qatar-reaches-bahrainis-nationalityswap/ [Consultado el 21 de noviembre de 2016].

WILKINSON, John Craven, Water and tribal settlement in South-East Arabia, Clarendon, Oxford, 1977.

ZACCARA, Luciano; SALDAÑA MARTIN, Marta, "Cambio y estabilidad política en las monarquías del Golfo tras la Primavera Árabe", en Revista CIDOB d'Afers Internacionals n.109, p. 177-199.

ZAHLAN, Rosemarie Said, The Making of the Modern Gulf States: Kuwait, Bahrain, Qatar, the United Arab Emirates and Oman, Garnet \& Ithaca Press, Reading, 1998.

\section{Documentos oficiales}

Bahrain's Constitution of 2002 with Amendments through 2012: http://www.legalaffairs.gov.bh/102. aspx?cms=iQRpheuphYt]6pyXUGiNqq6h9qKLgVAb (árabe) y https://www.constituteproject. org/constitution/Bahrain_2012?lang=en (inglés). [Consultado el 21 de noviembre de 2016].

Bahraini Citizenship Act - 1963: http://www.legalaffairs.gov.bh/Media/LegalPDF/K0863.pdf (árabe) y http://www.refworld.org/docid/3fb9f34f4.html (inglés). [Consultado el 21 de noviembre de 2016]. 
Kuwait's Constitution of 1962, Reinstated in 1992: https://www.constituteproject.org/constitution/ Kuwait_1992?lang=en. [Consultado el 21 de noviembre de 2016].

Kuwait Nationality Law, 1959: http://www.refworld.org/docid/3ae6b4ef1c.html [Consultado el 21 de noviembre de 2016].

Oman's Constitution of 1996 with Amendments through 2011: https://www.constituteproject.org/ constitution/Oman_2011?lang=en. [Consultado el 21 de noviembre de 2016]

Omani Citizenship Law 1983: http://www.rop.gov.om/english/roplaws.asp (inglés) http://gulfmigration. eu/database/legal_module/Oman/National Legal Framework/Citizenship and Statelessness/5.1 OLD Citizenship Law_AR.pdf (árabe). [Consultado el 21 de noviembre de 2016].

Oman: Sultan's Decree No. 38 of 2014 issuing the Omani Citizenship Law http://gulfmigration.eu/ database/legal_module/Oman/National Legal Framework/Citizenship and Statelessness/2.1 CS New Citizenship Law_AR.pdf (árabe). [Consultado el 21 de noviembre de 2016].

Qatar's Constitution of 2003: https://www.constituteproject.org/constitution/Qatar_2003?lang=en [Consultado el 21 de noviembre de 2016].

Qatar: Law No. 38 of 2005 on the acquisition of Qatari nationality 38 / 2005: http://www.almeezan.qa/ LawView.aspx?opt\&LawID=2591\&TYPE=PRINT\&language=ar (árabe) y http://www.almeezan. qa/LawView.aspx?opt\&LawID=2591\&TYPE=PRINT\&language=en (inglés) [Consultado el 21 de noviembre de 2016].

Saudi Arabia's Constitution of 1992 with Amendments through 2015: https://www.constituteproject. org/constitution/Saudi_Arabia_2013?lang=en [Consultado el 21 de noviembre de 2016].

Saudi Arabian Citizenship System: http://www.refworld.org/pdfid/3fb9eb6d2.pdf (inglés) y http://www. refworld.org/cgi-bin/texis/vtx/rwmain/opendocpdf.pdf?reldoc=y\&docid=5429543e4 (árabe). [Consultado el 21 de noviembre de 2016]

United Arab Emirates's Constitution of 1971 with Amendments through 2009: https://www. constituteproject.org/constitution/United_Arab_Emirates_2009?lang=en [Consultado el 21 de noviembre de 2016].

UAE: Federal Law No. 17 of 1972 Concerning Nationality and Passports http://www.gcc-legal.com/ LawAsPDF.aspx?opt\&country=2\&LawID=3147 (árabe) [Consultado el 21 de noviembre de 2016]. 


\section{RELACIONES INTERNACIONALES}

Revista académica cuatrimestral de publicación electrónica Grupo de Estudios de Relaciones Internacionales (GERI) Universidad Autónoma de Madrid, España

www.relacionesinternacionales.info

ISSN 1699 - 3950

ff facebook.com/RelacionesInternacionales

twitter.com/RRInternacional 